\title{
A Novel MOS-Channel Diode Embedded in a SiC Superjunction MOSFET for Enhanced Switching Performance and Superior Short Circuit Ruggedness
}

\author{
Jongwoon Yoon and Kwangsoo Kim *iD \\ Department of Electronic Engineering, Sogang University, Seoul 04107, Korea; yoon9508@naver.com \\ * Correspondence: kimks@sogang.ac.kr; Tel.: +82-2-705-8913
}

check for

updates

Citation: Yoon, J.; Kim, K. A Novel MOS-Channel Diode Embedded in a SiC Superjunction MOSFET for

Enhanced Switching Performance and Superior Short Circuit

Ruggedness. Electronics 2021, 10, 2619 https://doi.org/10.3390/

electronics10212619

Academic Editor: Giambattista Gruosso

Received: 9 October 2021

Accepted: 25 October 2021

Published: 27 October 2021

Publisher's Note: MDPI stays neutral with regard to jurisdictional claims in published maps and institutional affiliations.

Copyright: (c) 2021 by the authors. Licensee MDPI, Basel, Switzerland. This article is an open access article distributed under the terms and conditions of the Creative Commons Attribution (CC BY) license (https:/ / creativecommons.org/licenses/by/ $4.0 /)$.

\begin{abstract}
In this study, a novel MOS-channel diode embedded in a SiC superjunction MOSFET (MCD SJ-MOSFET) is proposed and analyzed by means of numerical TCAD simulations. Owing to the electric field shielding effect of the P+ body and the P-pillar, the channel diode oxide thickness $\left(t_{c o}\right)$ of MCD can be set to very thin while achieving a low maximum oxide electric field ( $\left.E_{M O X}\right)$ under $3 \mathrm{MV} / \mathrm{cm}$. Therefore, the turn-on voltage $\left(\mathrm{V}_{\mathrm{F}}\right)$ of the proposed structure was $1.43 \mathrm{~V}$, deactivating the parasitic PIN body diode. Compared with the SJ-MOSFET, the reverse recovery time $\left(t_{\mathrm{rr}}\right)$ and the reverse recovery charge $\left(\mathrm{Q}_{\mathrm{rr}}\right)$ were improved by $43 \%$ and $59 \%$, respectively. Although there is a slight increase in specific on-resistance $\left(\mathrm{R}_{\mathrm{ON}}\right)$, the MCD SJ-MOSFET shows very low input capacitance $\left(\mathrm{C}_{\mathrm{ISS}}\right)$ and gate to drain capacitance $\left(\mathrm{C}_{\mathrm{GD}}\right)$ due to the reduced active gate. Therefore, significantly improved figures of merit $\mathrm{R}_{\mathrm{ON}} \times \mathrm{C}_{\mathrm{GD}}$ by a factor of 4.3 are achieved compared to SJ-MOSFET. As a result, the proposed structure reduced the switching time as well as the switching energy loss $\left(\mathrm{E}_{\mathrm{SW}}\right)$. Moreover, electro-thermal simulation results show that the MCD SJ-MOSFET has a short circuit withstand time ( $\mathrm{t}_{\mathrm{SC}}$ ) more than twice that of the SJ-MOSFET at various DC bus voltages (400 and $600 \mathrm{~V}$ ).
\end{abstract}

Keywords: $\mathrm{SiC}$ MOSFET; superjunction; turn-on voltage; reverse recovery charge; gate drain capacitance; switching energy loss; short circuit withstand time

\section{Introduction}

Using the charge balance concept, superjunction (SJ) MOSFETs are considered as a promising approach to improve the trade-off between specific on-resistance $\left(\mathrm{R}_{\mathrm{ON}}\right)$ and breakdown voltage (BV) beyond silicon's (Si) limit [1]. Therefore, Si-based SJ-MOSFETs have become a dominant power switch recently in the BV range of 500-650 V. When it comes to higher voltage applications (1.2 kV or more), Si-based MOSFETs face material limitations, and silicon carbide ( $\mathrm{SiC}$ ) SJ-MOSFETs are spotlighted as promising devices [2]. It has been experimentally proven that the SJ concept in $\mathrm{SiC}$ devices can achieve an ultra-low $\mathrm{R}_{\mathrm{ON}}$ while maintaining high BV due to the superior material properties [3-7]. Meanwhile, the wide depletion region of SJ-MOSFETs causes extensive reverse recovery charge $\left(\mathrm{Q}_{\mathrm{RR}}\right)$, which limits their usage in hard-switching configuration [8,9]. Additionally, the parasitic PIN body diode of the SiC MOSFET features a relatively higher turn-on voltage $(\sim 3 \mathrm{~V})$ than its Si MOSFET counterpart $(\sim 0.7 \mathrm{~V})$, owing to the wide band gap properties, which further deteriorates the reverse recovery characteristics. As a result, anti-paralleled external Schottky barrier diodes (SBDs) are normally used in power modules to suppress the activation of the PIN diode. However, it was found that the parasitic inductance between the MOSFET and the external SBD has a great effect on the conduction power loss [10].

The integration of a unipolar diode into SiC SJ-MOSFETs is an attractive option, as it can reduce chip size and prevent parasitic inductance component. Recently, research was conducted to improve the reverse recovery characteristics by embedding a p-type SBD in the drain side of a SiC SJ-MOSFET [11,12]. However, the fabrication process for integrating p-type SBD is too complicated and cost demanding. Additionally, several studies found 
that integrated SBDs cause high leakage current induced by thermionic field emission in short circuit stress, which lowers the device reliability and narrows the short circuit safe operating area (SCSOA) [13-15]. Moreover, the SBD region in SiC MOSFET may suffer from void issues or Schottky barrier height lowering after short circuit stress [16].

Recently, several studies demonstrated that integrating an MOS-channel diode (MCD) is another option for enhancing reverse recovery characteristics $[17,18]$. The oxide thickness of the MCD is reduced in order to achieve a desired turn-on voltage $\left(\mathrm{V}_{\mathrm{F}}\right)$, so as to suppress the minority carrier injection from the PIN diode. In addition, some studies adopting the MCD concept in SiC MOSFETs have been conducted [19,20]. However, the thinned oxide layer of MCD increases the maximum oxide electric field ( $E_{M O X}$ ) to nearly $4 \mathrm{MV} / \mathrm{cm}$, which may result in oxide breakdown or shorten the lifespan of SiC MOSFETs. Krishnaswami et al. reported that an $\mathrm{E}_{\mathrm{MOX}}$ under $3 \mathrm{MV} / \mathrm{cm}$ can ensure the gate oxide's reliability [21]. As a result, concerns about a high oxide electric field make it difficult to maximize the benefits of $\mathrm{MCD}$, producing a relatively high $\mathrm{V}_{\mathrm{F}}$ compared to SBDs embedded in SiC MOSFETs. Thus, this will limit their usage in high-voltage applications.

In this study, a novel $1.2 \mathrm{kV}$ class MOS-channel diode embedded in a $\mathrm{SiC}$ superjunction MOSFET (MCD SJ-MOSFET) is proposed and analyzed by numerical Sentaurus TCAD simulation compared with a $\mathrm{SiC}$ superjunction MOSFET (SJ-MOSFET). Applying the MCD concept in a $650 \mathrm{~V}$ class Si SJ-MOSFET was implemented previously [22], but no attempts have been made to do so for the SiC SJ-MOSFET. Moreover, the short circuit characteristics of MCDs embedded in SiC MOSFETs have not been studied yet. The P+ body and the P-pillar regions of the MCD SJ-MOSFET can simultaneously dissipate the electric field, so that the oxide thickness of MCD can be set to very thin while achieving acceptable $\mathrm{E}_{\mathrm{MOx}}$. Due to the low $V_{F}$ of the MCD, the MCD SJ-MOSFET can greatly improve the reverse recovery characteristics compared with the SJ-MOSFET, while deactivating the parasitic body diode. In addition, the MCD SJ-MOSFET not only greatly reduces the switching energy loss, but also reduces the switching time due to the low input capacitance ( $\left.\mathrm{C}_{\mathrm{ISS}}\right)$ and gate drain capacitance $\left(\mathrm{C}_{\mathrm{GD}}\right)$. Additionally, electro-thermal simulation results show that the MCD SJ-MOSFET boasts superior short circuit performance compared to the SJ-MOSFET.

\section{Device Structures and Simulation Background}

The physical models used in the Sentaurus TCAD simulation contain bandgap narrowing (BGN) and Fermi-Dirac statistics. The recombination models contain Auger, Shockley-Read-Hall (SRH), the doping-dependent model and the temperature-dependent model [23]. The incomplete ionization and Hatakeyama avalanche models are also included. The mobility model contained the doping-dependent Arora model, Enormal and high field saturation. The anisotropic behavior in mobility and temperature characteristics of the $\mathrm{SiC}$ are also taken into consideration. A fixed charge concentration of $1 \times 10^{12} \mathrm{~cm}^{-2}$ was included at the $\mathrm{SiC} / \mathrm{SiO}_{2}$ interface for all of the devices [24]. For electro-thermal mixed-mode simulation in short circuit characteristics, the thermodynamic model and analytic TEPower model are considered to describe self-heating effects and thermoelectric powers in nondegenerate semiconductors [25].

Figure 1 represents the schematic cross-sectional views and dimension parameters of the SJ-MOSFET and MCD SJ-MOSFET. The doping and dimension parameters of the two devices refer to published work [20]. Both devices feature the same doping and dimension parameters, except for the gate structure. The active gate extends over the P-base region, set to $0.2 \mu \mathrm{m}$ in our proposed device. The doping concentration of the JFET region in both structures is set $1 \times 10^{17} \mathrm{~cm}^{-3}$ to reduce the $R_{\mathrm{ON}}$. The body region of SiC MOSFET should be well designed because it has great influence not only on device performance, but also on device reliability [26]. We adopted shielded planar topology in this study, which features a P+ body region under the channel region [27]. Several studies have shown that the P+ region below the channel improves the short circuit capability of the device $[25,28]$. To obtain the charge balancing effect, the width of the P-pillar was set to $1.25 \mu \mathrm{m}$ to occupy half of the cell pitch $(5 \mu \mathrm{m})$, and it had the same doping concentration as that of the N-pillar. 
Figure 2 shows the influence of the pillar doping concentration on static characteristics in MCD SJ-MOSFET. In this study, we set the doping concentration of both pillar regions at $3.75 \times 10^{16} \mathrm{~cm}^{-3}$, which achieves the highest Baliga's figure of merit $\left(B F O M=B^{2} / R_{O N}\right)$.

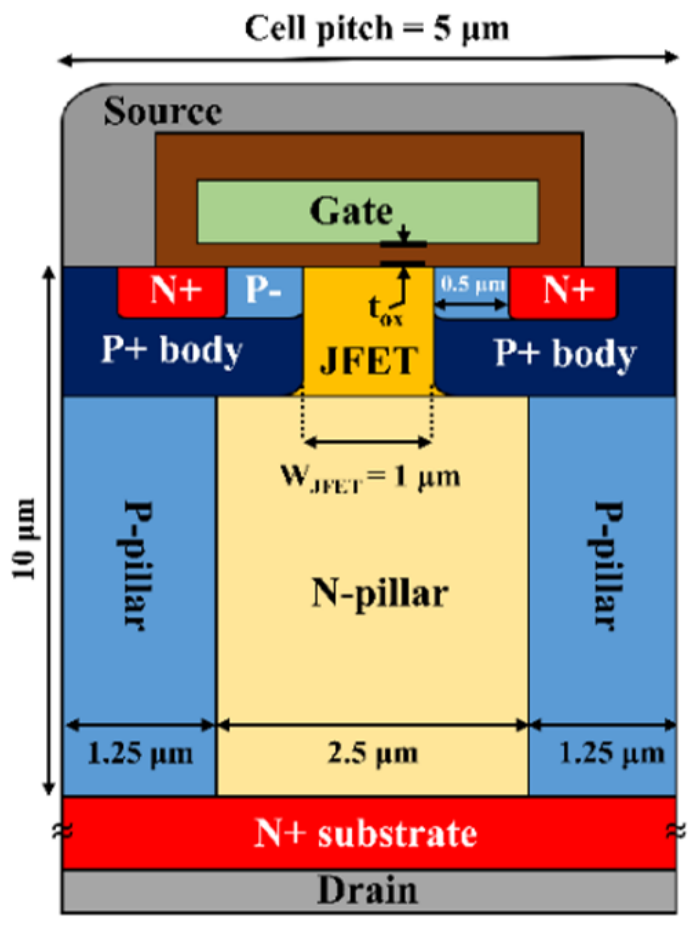

(a)

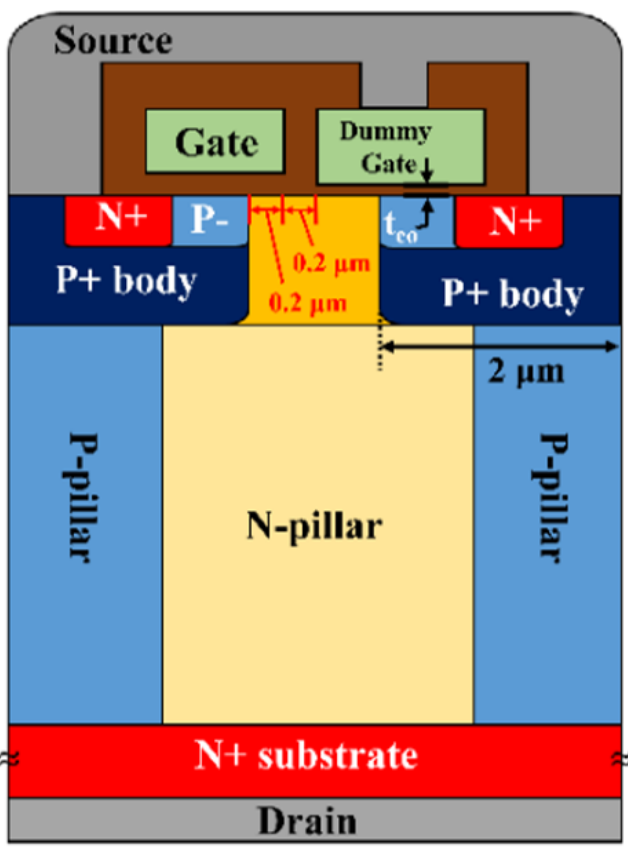

(b)

Figure 1. Schematic cross-sectional views of (a) SJ-MOSFET and (b) MCD SJ-MOSFET.

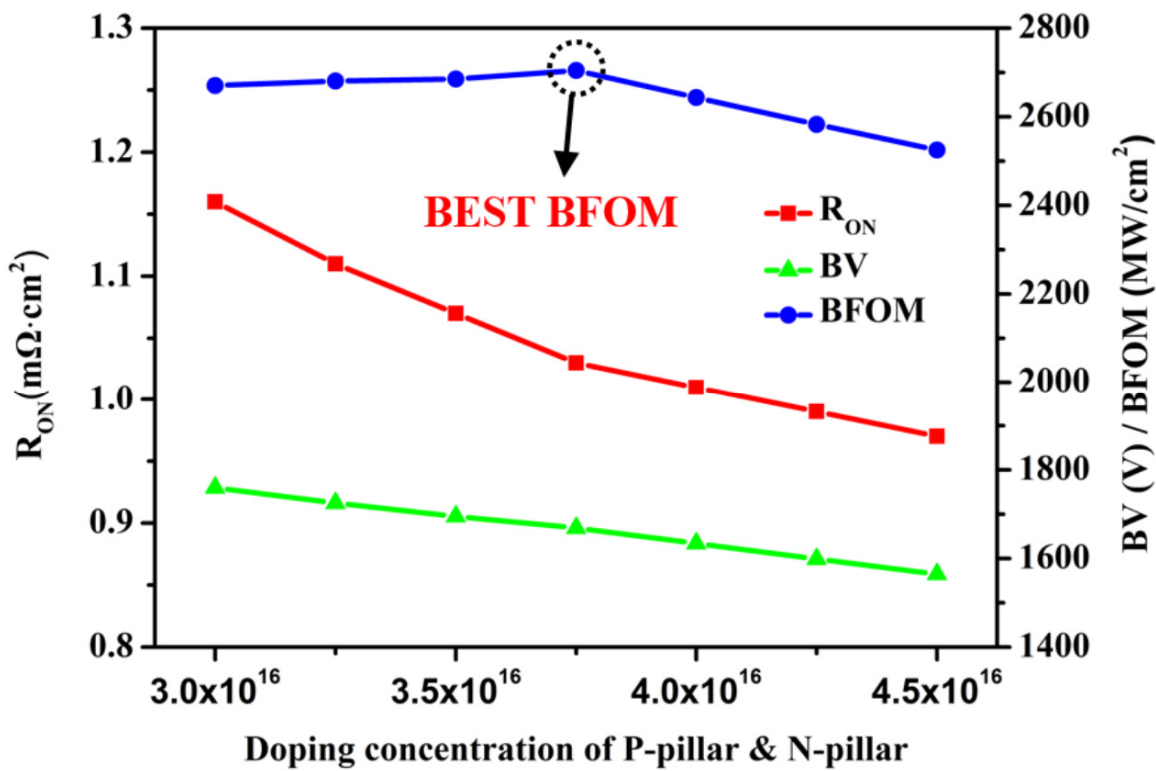

Figure 2. Influence of the pillar doping concentration on static characteristics in the MCD SJ-MOSFET. $\mathrm{R}_{\mathrm{ON}}$ is obtained at $\mathrm{V}_{\mathrm{GS}}=15 \mathrm{~V}$ and $\mathrm{I}_{\mathrm{DS}}=100 \mathrm{~A} / \mathrm{cm}^{2}$. BV is obtained at $\mathrm{V}_{\mathrm{GS}}=0 \mathrm{~V}$ and $\mathrm{I}_{\mathrm{DS}}=1 \mu \mathrm{A} / \mathrm{cm}^{2}$.

The dummy gate electrically connected to the source electrode features thinner channel diode oxide thickness $\left(t_{\mathrm{co}}\right)$ than the active gate oxide thickness $\left(t_{\mathrm{ox}}=50 \mathrm{~nm}\right)$, which acts as a channel diode. Figure $3 a$ shows the influence of $t_{c o}$ on the reverse conduction characteristics of the MCD SJ-MOSFET in the third quadrant with comparison to the SJ-MOSFET. The result clearly shows that a smaller $t_{c o}$ leads to a faster turn-on in the proposed device 
because of the decreasing threshold voltage $\left(\mathrm{V}_{\mathrm{TH}}\right)$ of the MCD. However, since the thinner $t_{c o}$ increases $E_{M O X}$, the trade-off between $V_{F}$ and $E_{M O X}$ must be discussed. Figure 4a shows the $E_{M O X}$ and $V_{F}$ relationship of MCD SJ-MOSFET according to the change in $t_{\mathrm{co}}$. To meet the $3 \mathrm{MV} / \mathrm{cm}$ oxide reliability limit, $\mathrm{t}_{\mathrm{co}}=10 \mathrm{~nm}$ was chosen for the MCD SJ-MOSFET with an $\mathrm{E}_{\mathrm{MOX}}$ of $2.95 \mathrm{MV} / \mathrm{cm}$, as shown in Figure $4 \mathrm{~b}$. It seems that owing to the electric field shielding effect of the P+ body and the P-pillar, the electric field near the oxide can be effectively suppressed and the $t_{c o}$ can be very thin. The $V_{F}$ of the proposed structure was $1.43 \mathrm{~V}$, which was a similar level to that of the SBD-embedded SiC MOSFET $[24,29]$. The hole density distribution at $\mathrm{I}_{\mathrm{DS}}=-100 \mathrm{~A} / \mathrm{cm}^{2}$ and $\mathrm{V}_{\mathrm{GS}}=-5 \mathrm{~V}$ for both devices is shown in Figure $3 b, c$, respectively. In MCD SJ-MOSFET, minority carrier injection was greatly suppressed in the JFET and the N-pillar region, which means deactivation of the parasitic body diode. Therefore, the MCD SJ-MOSFET can prevent the bipolar degradation issue caused by the body diode [30]. The detailed device parameters of both structures are listed in Table 1.

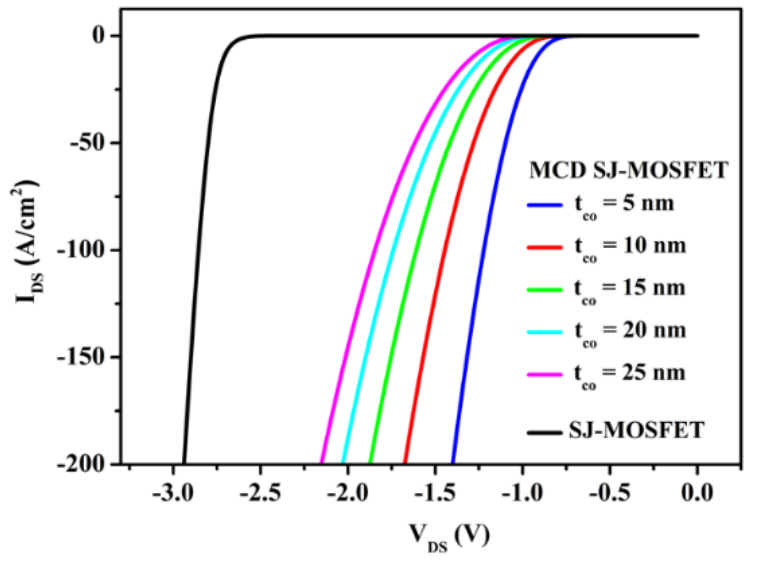

(a)

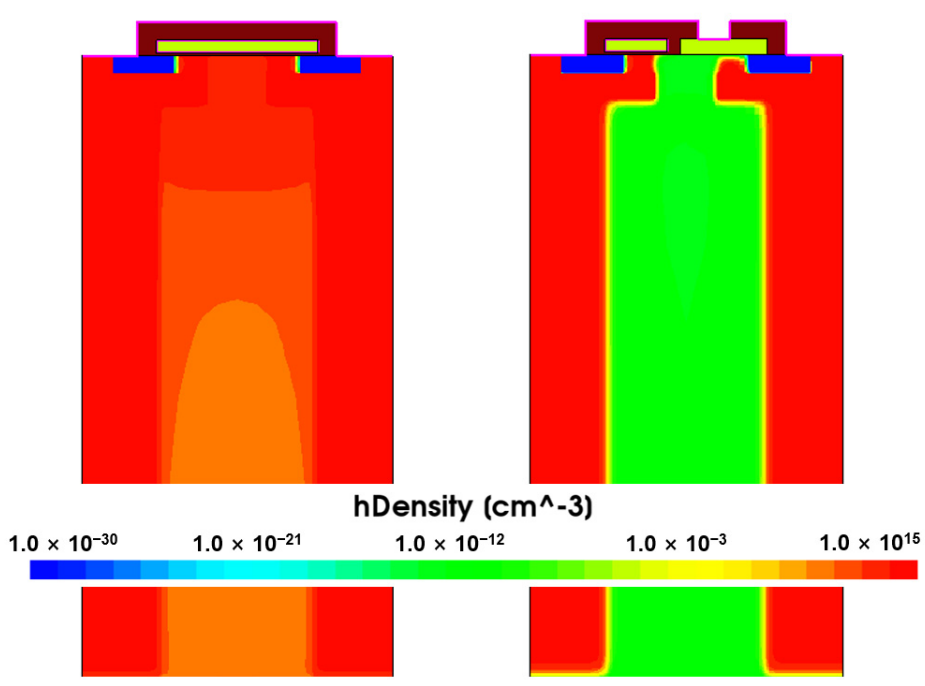

(b)

(c)

Figure 3. (a) Influence of $t_{c o}$ on the reverse conduction characteristics in the MCD SJ-MOSFET in comparison to the SJ-MOSFET at $\mathrm{V}_{\mathrm{GS}}=-5 \mathrm{~V}$. Hole density distribution at $\mathrm{I}_{\mathrm{DS}}=-100 \mathrm{~A} / \mathrm{cm}^{2}$ and $\mathrm{V}_{\mathrm{GS}}=-5 \mathrm{~V}$ for the (b) SJ-MOSFET and (c) MCD SJ-MOSFET (when $\mathrm{t}_{\mathrm{co}}=10 \mathrm{~nm}$ ).

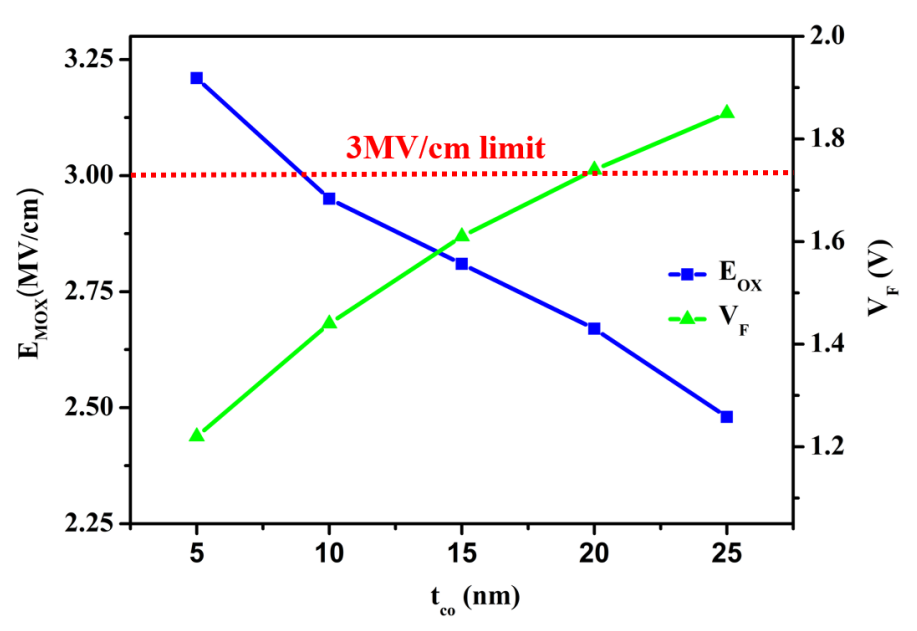

(a)

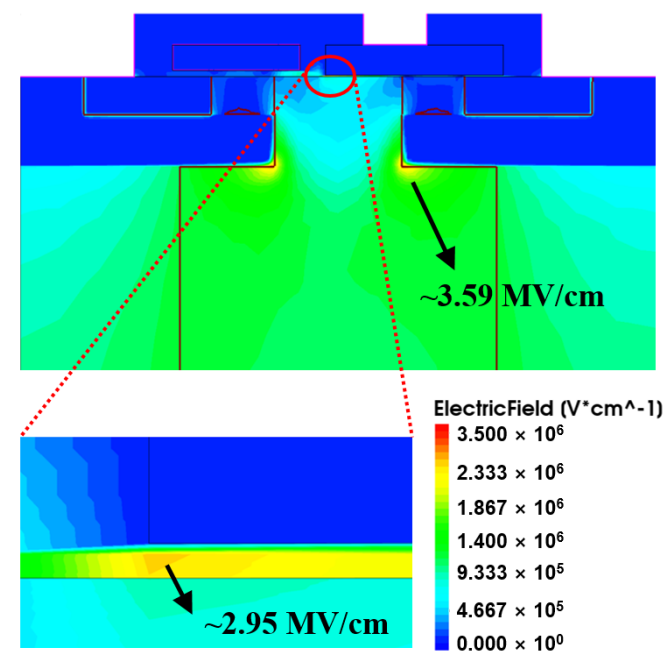

(b)

Figure 4. (a) Maximum oxide electric field ( $\left.\mathrm{E}_{\mathrm{MOX}}\right)$ and turn-on voltage $\left(\mathrm{V}_{\mathrm{F}}\right)$ changes of the MCD SJ-MOSFET according to the change $t_{\mathrm{co}}$, (b) electric field distributions of the MCD SJ-MOSFET (when $\mathrm{t}_{\mathrm{co}}=10 \mathrm{~nm}$ ). 
Table 1. Device parameters for TCAD simulation.

\begin{tabular}{ccc}
\hline Parameter & SJ- & MCD- \\
\hline Drift layer thickness $(\mu \mathrm{m})$ & 10 & 10 \\
N-pillar $/$ P-pillar doping $\left(\mathrm{cm}^{-3}\right)$ & $3.75 \times 10^{16}$ & $3.75 \times 10^{16}$ \\
JFET doping $\left(\mathrm{cm}^{-3}\right)$ & $1 \times 10^{17}$ & $1 \times 10^{17}$ \\
Channel length $(\mu \mathrm{m})$ & 0.5 & 0.5 \\
N+ substrate thickness $(\mu \mathrm{m})$ & 100 & 100 \\
N+ substrate doping $\left(\mathrm{cm}^{-3}\right)$ & $1 \times 10^{19}$ & $1 \times 10^{19}$ \\
Channel doping $\left(\mathrm{cm}^{-3}\right)$ & $1 \times 10^{17}$ & $1 \times 10^{17}$ \\
P+ body doping $\left(\mathrm{cm}^{-3}\right)$ & $5 \times 10^{18}$ & $5 \times 10^{18}$ \\
N+ source doping $\left(\mathrm{cm}^{-3}\right)$ & $1 \times 10^{19}$ & $1 \times 10^{19}$ \\
EFP region doping $\left(\mathrm{cm}^{-3}\right)$ & $5 \times 10^{18}$ & $5 \times 10^{18}$ \\
Width of P-pillar $\left(\mu \mathrm{m}^{18}\right.$ & 1.25 & 1.25 \\
Cell pitch $(\mu \mathrm{m})$ & 5 & 5 \\
Width of JFET $(\mu \mathrm{m})$ & 1 & 1 \\
$t_{\mathrm{ox}}(\mathrm{nm})$ & 50 & 50 \\
$\mathrm{t}_{\mathrm{co}}(\mathrm{nm})$ & - & 10 \\
Distance of the active gate extend & - & 0.2 \\
over the channel $(\mu \mathrm{m})$ & &
\end{tabular}

The proposed device could be fabricated in a similar way compared to the SJ-MOSFET. Only one additional mask is required to form the stepped oxide, and the separation of the dummy gate and the active gate can be performed simultaneously in the subsequent etching process after $\mathrm{N}+$ polysilicon deposition $[17,20]$. Additionally, the source contact hole etching process of the dummy gate can be performed simultaneously in the ohmic contact hole etching process.

\section{Results and Discussion}

\subsection{Electrical Characteristics}

Figure 5 represents the I-V characteristics of both devices. In this study, BV was obtained at $\mathrm{V}_{\mathrm{GS}}=0 \mathrm{~V}$ and $\mathrm{I}_{\mathrm{DS}}=1 \mu \mathrm{A} / \mathrm{cm}^{2}$ and $\mathrm{R}_{\mathrm{ON}}$ was obtained at $\mathrm{V}_{\mathrm{GS}}=15 \mathrm{~V}$ and $\mathrm{I}_{\mathrm{DS}}=100 \mathrm{~A} / \mathrm{cm}^{2}$. The MCD SJ-MOSFET has a slightly higher $\mathrm{R}_{\mathrm{ON}}\left(1.03 \mathrm{~m} \Omega \cdot \mathrm{cm}^{2}\right)$ than the SJ-MOSFET $\left(0.91 \mathrm{~m} \Omega \cdot \mathrm{cm}^{2}\right)$, because current flows through only one active gate. However, it still achieved low $\mathrm{R}_{\mathrm{ON}}$ level due to the high concentration of JFET region and SJ structure. It can be seen that the proposed structure has about $46 \%$ lower saturation current at $\mathrm{V}_{\mathrm{DS}}=600 \mathrm{~V}$ compared to the SJ-MOSFET. Since the short circuit withstand time ( $\left.\mathrm{t}_{\mathrm{SC}}\right)$ and saturation current are usually inversely proportional, it is very helpful for short circuit characteristics [31]. The proposed device has slightly higher BV $(1669 \mathrm{~V})$ than the SJMOSFET $(1654 \mathrm{~V})$, given that the electric field was concentrated on the dummy gate, owing to its thin $t_{\mathrm{co}}$.

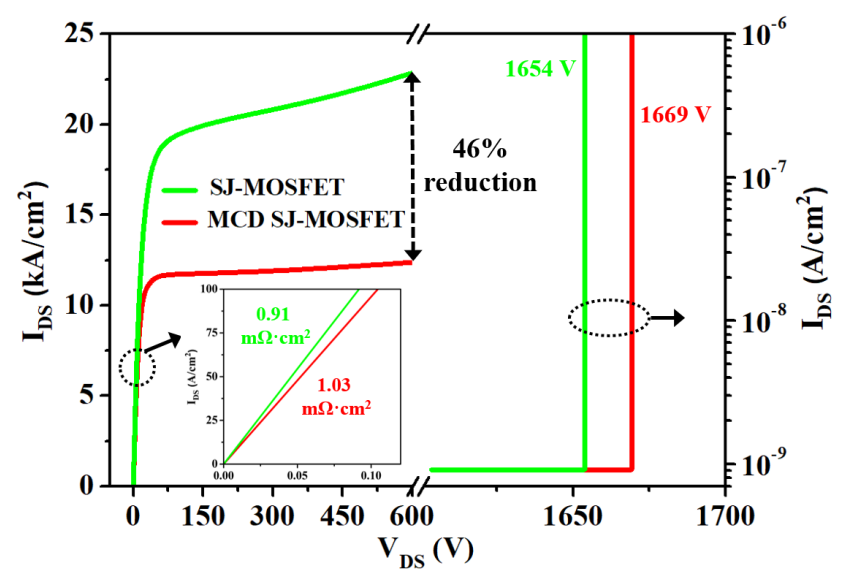

Figure 5. I-V characteristics of both devices. The output characteristics are obtained at $\mathrm{V}_{\mathrm{GS}}=15 \mathrm{~V}$ and the blocking characteristics are obtained when $\mathrm{V}_{\mathrm{GS}}=0 \mathrm{~V}$. 
Figure 6a compares the reverse recovery characteristics of both devices. Additionally, the double pulse test circuit used in reverse recovery simulation is shown in Figure $6 \mathrm{~b}$. The lower arm MOSFET is used as a switch and the upper arm MOSFET is the actual device under test (DUT). The stray inductance and the gate resistance are $10 \mathrm{nH}$ and $20 \Omega$, respectively. The load current is set to $500 \mathrm{~A} / \mathrm{cm}^{2}$ and the drain bias is set to $600 \mathrm{~V}$. In order to make the channel turn off and act as a diode mode, $\mathrm{V}_{\mathrm{GS}}=-5 \mathrm{~V}$ was applied in DUT. The results show that the peak reverse recovery current $\mathrm{I}_{\mathrm{RRM}}$ of the MCD SJ-MOSFET is $206 \mathrm{~A} / \mathrm{cm}^{2}$, which is much lower than that of SJ-MOSFET $\left(324 \mathrm{~A} / \mathrm{cm}^{2}\right)$. In addition, the reverse recovery time $\left(t_{\mathrm{rr}}\right)$ and the reverse recovery charge $\left(Q_{\mathrm{rr}}\right)$ were improved by $43 \%$ and $59 \%$, respectively, compared to the SJ-MOSFET. Here, the $\mathrm{Q}_{\mathrm{rr}}$ is defined in the following equation:

$$
\mathrm{Q}_{\mathrm{rr}}=\int_{0}^{\mathrm{t}_{\mathrm{rr}}} \mathrm{I}_{\mathrm{DS}} \mathrm{dt}
$$

where $t_{r r}$ is defined as the time from when the reverse recovery current crosses zero to the time when the reverse recovery current drops down to $10 \%$ of the $\mathrm{I}_{\text {RRM }}$. Figure 7 compares the $\mathrm{C}-\mathrm{V}$ characteristics of both devices. In the MCD SJ-MOSFET, the input capacitance $\left(C_{I S S}=C_{G S}+C_{G D}\right)$ decreased by $46 \%$ due to the reduced active gate area when $V_{D S}=600 \mathrm{~V}$. Moreover, the $\mathrm{C}_{\mathrm{GD}}$ of the MCD SJ-MOSFET is greatly reduced (79\%) when $\mathrm{V}_{\mathrm{DS}}=600 \mathrm{~V}$ because of the reduced active gate area and depletion region capacitance caused by sourcecontacted dummy gate [32]. A comprehensive comparison of the device characteristics is shown in Table 2. Although BFOM is slightly decreased by $10 \%$, it can be seen that the MCD SJ-MOSFET significantly improved the figures of merit $\mathrm{R}_{\mathrm{ON}} \times \mathrm{C}_{\mathrm{GD}}$ by a factor of 4.3 compared to the SJ-MOSFET. As a result, these improvements indicate that the MCD SJ-MOSFET is more suitable for high-frequency applications.

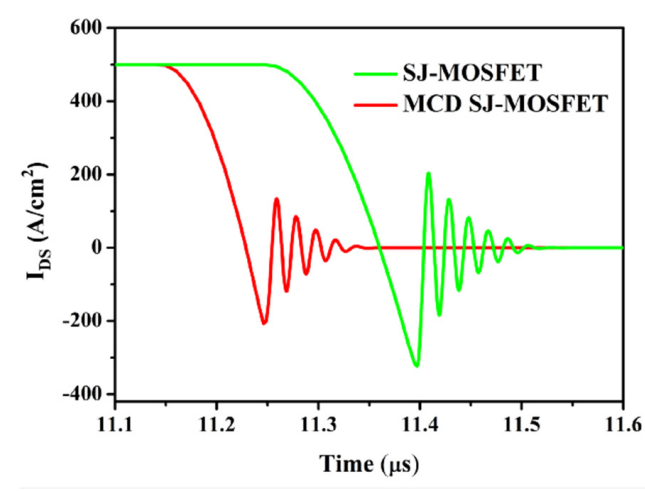

(a)

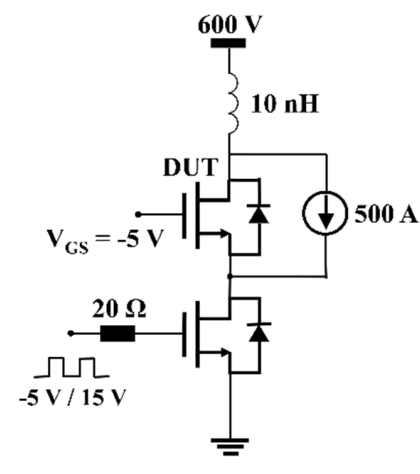

(b)

Figure 6. (a) Reverse recovery characteristics of both devices, (b) Double pulse test circuit used in reverse recovery simulation. The active area of the device under test (DUT) and lower arm MOSFET is $1 \mathrm{~cm}^{2}$.

Table 2. Comparison of device characteristics.

\begin{tabular}{cccc}
\hline & SJ- & MCD- & Unit \\
\hline $\mathrm{V}_{\mathrm{F}}$ & 2.86 & 1.43 & $\mathrm{~V}$ \\
${ }^{1} \mathrm{BV}$ & 1654 & 1669 & $\mathrm{~V}$ \\
${ }^{2} \mathrm{R}_{\mathrm{ON}}$ & 0.91 & 1.03 & $\mathrm{~m} \Omega \cdot \mathrm{cm}^{2}$ \\
${ }^{\mathrm{BFOM}}$ & 3006 & 2704 & $\mathrm{MW} / \mathrm{cm}^{2}$ \\
${ }^{3} \mathrm{C}_{\mathrm{ISS}}$ & 27.1 & 14.5 & $\mathrm{nF} / \mathrm{cm}^{2}$ \\
${ }^{3} \mathrm{C}_{\mathrm{GD}}$ & 21.2 & 4.4 & $\mathrm{pF} / \mathrm{cm}^{2}$ \\
$\mathrm{R}_{\mathrm{ON}} \times \mathrm{C}_{\mathrm{GD}}$ & 19.3 & 4.5 & $\mathrm{~m} \Omega \cdot \mathrm{pF}^{2}$ \\
$\mathrm{I}_{\mathrm{RRM}}$ & 324 & 206 & $\mathrm{~A} / \mathrm{cm}^{2}$ \\
$\mathrm{t}_{\mathrm{rr}}$ & 44 & 25 & $\mathrm{~ns}$ \\
$\mathrm{Q}_{\mathrm{rr}}$ & 7270 & 2999 & $\mathrm{nC} / \mathrm{cm}^{2}$
\end{tabular}

${ }^{1} \mathrm{BV}$ was obtained at $\mathrm{V}_{\mathrm{GS}}=0 \mathrm{~V}$ and $\mathrm{I}_{\mathrm{DS}}=1 \mu \mathrm{A} / \mathrm{cm}^{2} .{ }^{2} \mathrm{R}_{\mathrm{ON}}$ was obtained at $\mathrm{V}_{\mathrm{GS}}=15 \mathrm{~V}$ and $\mathrm{I}_{\mathrm{DS}}=100 \mathrm{~A} / \mathrm{cm}^{2}$.

${ }^{3} \mathrm{C}_{\mathrm{ISS}}$ and $\mathrm{C}_{\mathrm{GD}}$ were obtained at $\mathrm{V}_{\mathrm{DS}}=600 \mathrm{~V}$. 


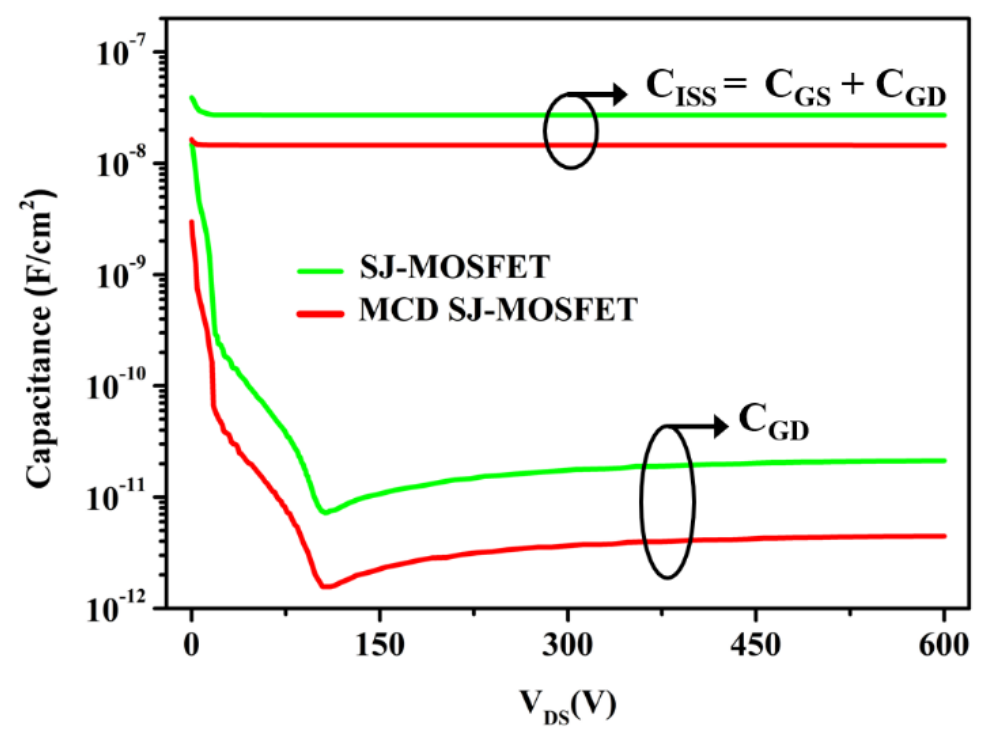

Figure 7. $\mathrm{C}-\mathrm{V}$ characteristics of the SJ-MOSFET and MCD SJ-MOSFET. When $\mathrm{V}_{\mathrm{GS}}=0 \mathrm{~V}, \mathrm{AC}$ signal of $1 \mathrm{MHz}$.

Thereafter, the switching performance analysis of both devices was conducted using double pulse test circuit in Figure 6b. The lower arm MOSFET was the actual DUT and the body diode of the DUT (i.e., upper arm MOSFET) was used as a freewheeling diode. Figure 8a,b show the switching waveforms of both devices. Due to the large reduction in $\mathrm{C}_{\mathrm{ISS}}$ and $\mathrm{C}_{\mathrm{GD}}$, the MCD SJ-MOSFET has a short miller plateau region and a large $\mathrm{dV}_{\mathrm{GS}} / \mathrm{dt}$. As a result, the turn-off time ( $\mathrm{T}_{\mathrm{OFF}}=$ from $90 \%$ of $\mathrm{V}_{\mathrm{GS}}$ to $90 \%$ of $\mathrm{V}_{\mathrm{DS}}$ ) and the turn-on time $\left(\mathrm{T}_{\mathrm{ON}}=\right.$ from $10 \%$ of $\mathrm{V}_{\mathrm{GS}}$ to $10 \%$ of $\left.\mathrm{V}_{\mathrm{DS}}\right)$ of the proposed device is reduced by $56 \%$ and $39 \%$, respectively, compared to the SJ-MOSFET. It seems that the overshoot current of the MCD SJ-MOSFET is much lower than that of SJ-MOSFET because of the large reduction in the reverse recovery charge of the upper arm MOSFET [24]. This will further decrease the turn-on switching energy loss $\left(\mathrm{E}_{\mathrm{ON}}\right)$. Figure $8 \mathrm{c}$ compares the switching energy loss of both devices. $\mathrm{E}_{\mathrm{ON}}$ and $\mathrm{E}_{\mathrm{OFF}}$ are given by the following equations:

$$
\begin{gathered}
\mathrm{E}_{\mathrm{ON}}=\int_{0}^{\mathrm{T}_{\mathrm{ON}}} \mathrm{V}_{\mathrm{DS}} \cdot \mathrm{I}_{\mathrm{DS}} \mathrm{dt} \\
\mathrm{E}_{\mathrm{OFF}}=\int_{0}^{\mathrm{T}_{\mathrm{OFF}}} \mathrm{V}_{\mathrm{DS}} \cdot \mathrm{I}_{\mathrm{DS}} \mathrm{dt}
\end{gathered}
$$

Owing to the faster switching time and enhanced reverse recovery characteristics, the switching energy loss $\left(\mathrm{E}_{\mathrm{SW}}=\mathrm{E}_{\mathrm{ON}}+\mathrm{E}_{\mathrm{OFF}}\right)$ of the proposed device is improved by $48.6 \%$ compared to SJ-MOSFET. The detailed switching characteristics are summarized in Table 3.

Table 3. Comparison of device characteristics.

\begin{tabular}{cccc}
\hline & SJ- & MCD- & Unit \\
\hline$T_{\text {OFF }}$ & 750 & 331 & $\mathrm{~ns}$ \\
$T_{\text {ON }}$ & 317 & 194 & $\mathrm{~ns}$ \\
$E_{\text {OFF }}$ & 20.03 & 9.43 & $\mathrm{~mJ} / \mathrm{cm}^{2}$ \\
$E_{\text {ON }}$ & 24.05 & 13.24 & $\mathrm{~mJ} / \mathrm{cm}^{2}$ \\
ESW $_{\text {SW }}$ & 44.08 & 22.67 & $\mathrm{~mJ} / \mathrm{cm}^{2}$ \\
\hline
\end{tabular}




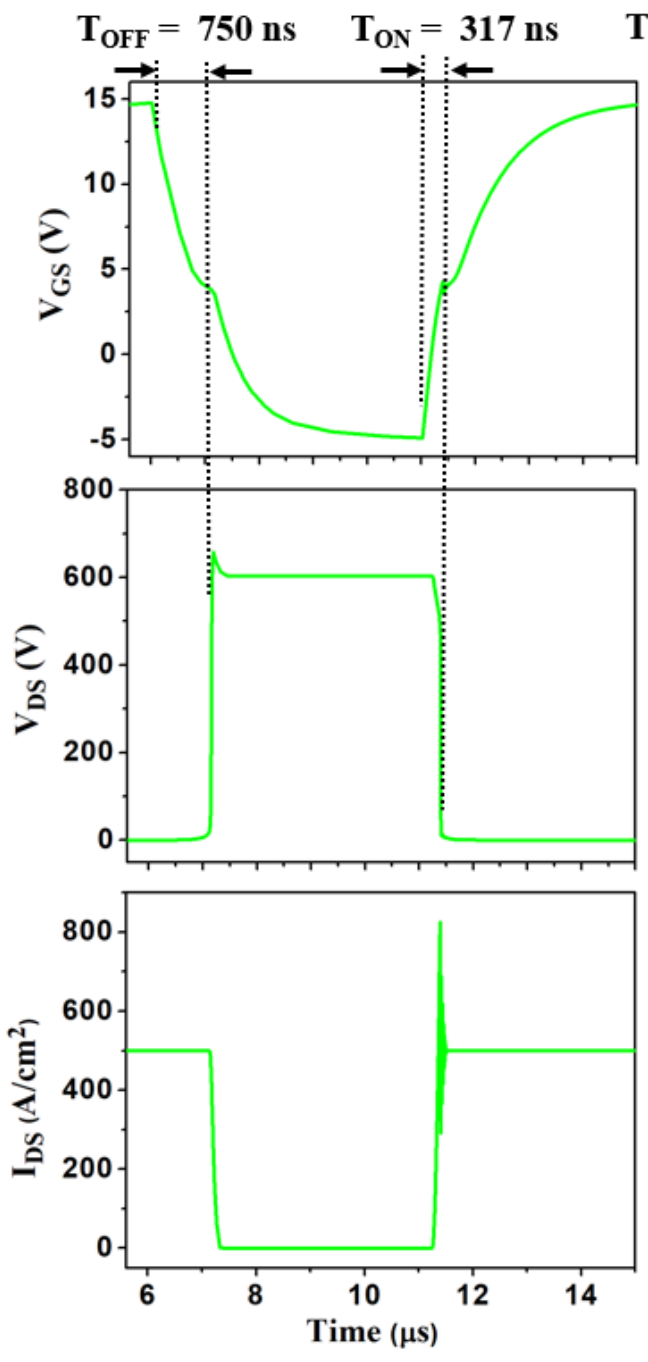

(a)
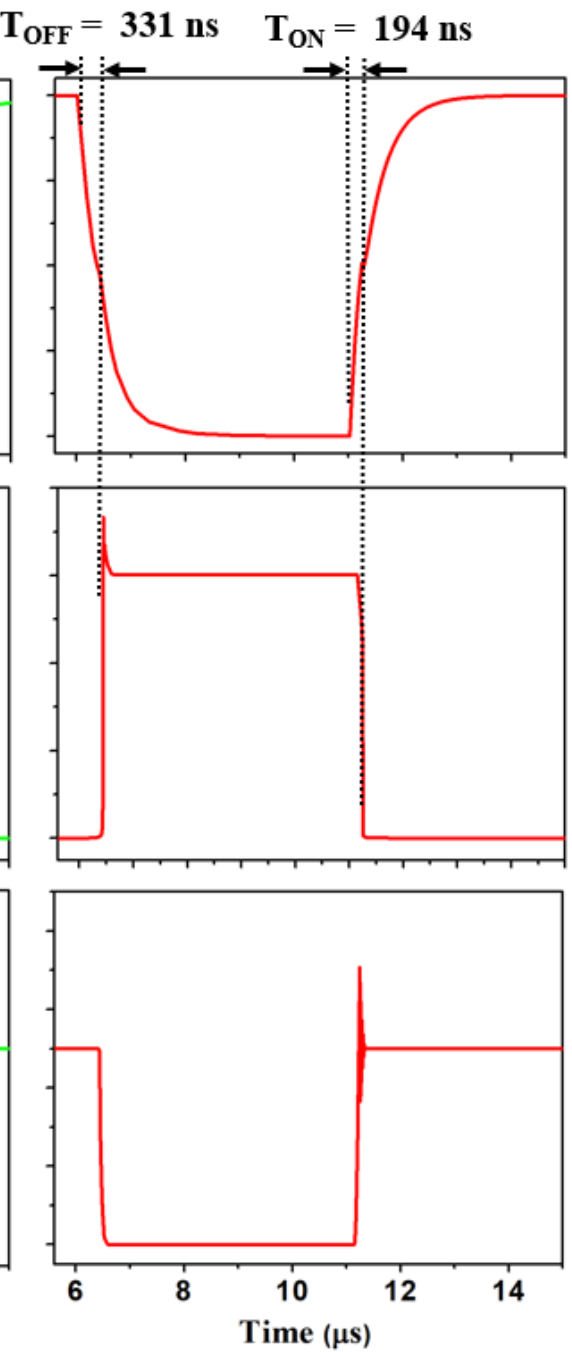

(b)

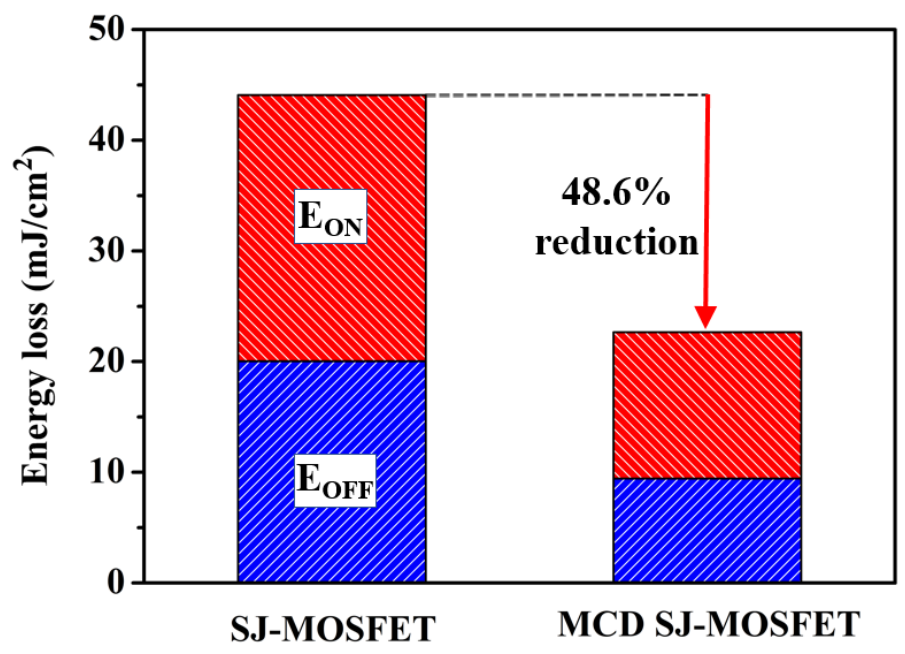

(c)

Figure 8. Switching waveforms of the (a) SJ-MOSFET and (b) MCD SJ-MOSFET. (c) Switching energy loss diagrams of both devices. 


\subsection{Short Circuit Characteristics}

Short circuit ruggedness is one of the most crucial reliability issues in SiC MOSFETs because high voltage and high current are applied to the small cell area, resulting in high power dissipation $[33,34]$. Therefore, SiC MOSFETs with improved short circuit characteristics are essential. In this section, short circuit characteristics of both devices are investigated by means of electro-thermal mixed-mode TCAD simulation. The test circuit schematic is shown in Figure 9. The turn-on and turn-off gate voltage are set to 15 and $0 \mathrm{~V}$, respectively, while the DC bus ranges from 400 to $600 \mathrm{~V}$. The external gate resistance $\left(R_{G}\right)$ is $10 \Omega$.

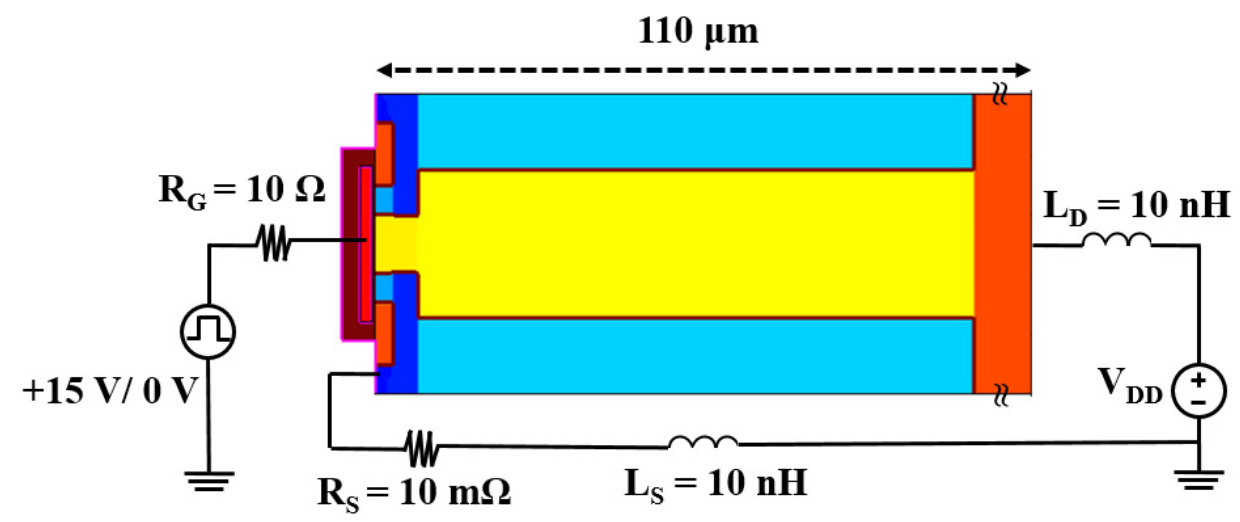

Figure 9. Short circuit simulation schematic.

Figure 10 shows the short circuit current and the maximum temperature $\left(\mathrm{T}_{\mathrm{MAX}}\right)$ waveforms of both devices with different pulse widths at a low drain bias $\left(\mathrm{V}_{\mathrm{DD}}=400 \mathrm{~V}\right)$. Here, $\mathrm{T}_{\mathrm{MAX}}$ means the highest temperature in the device during short circuit simulation. Notably, two unique characteristics can be found in the short circuit current waveforms; the positive slope of the short circuit current at the end of the pulse and the increasing tail current with longer pulse width at turn-off state. This phenomenon is caused by leakage current at the PN junction due to the extremely high temperature, and has already been reported in several studies [35-37]. The $t_{S C}$ of the MCD SJ-MOSFET is $22.5 \mu \mathrm{s}$, which is about two times longer than that of the SJ-MOSFET $(11 \mu \mathrm{s})$. The energy dissipation during the short circuit state $\left(\mathrm{E}_{\mathrm{SC}}\right)$ is defined as:

$$
\mathrm{E}_{\mathrm{SC}}=\int_{0}^{\mathrm{tSC}_{\mathrm{SC}}} \mathrm{V}_{\mathrm{DS}} \cdot \mathrm{I}_{\mathrm{DS}} \mathrm{dt}
$$

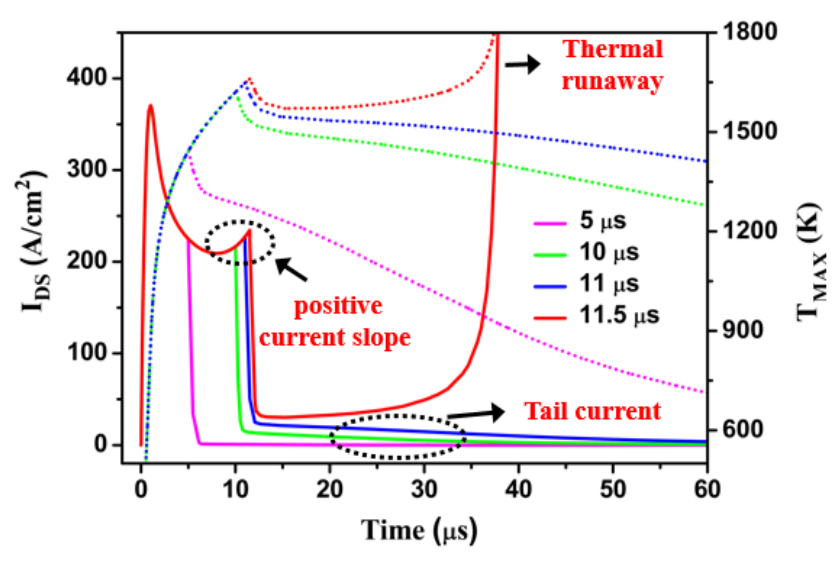

(a)

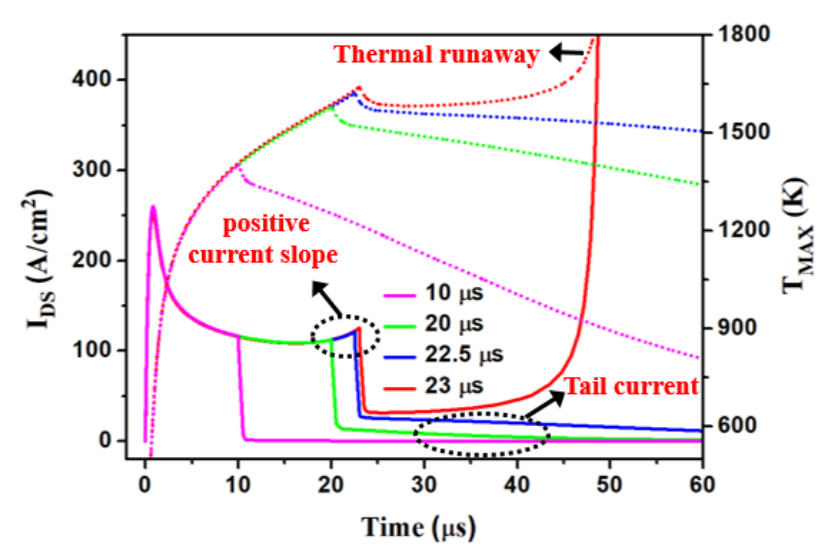

(b)

Figure 10. Simulated short circuit current and maximum temperature $\left(\mathrm{T}_{\mathrm{MAX}}\right)$ waveforms of the (a) SJ-MOSFET and (b) MCD SJ-MOSFET at $\mathrm{V}_{\mathrm{DD}}=400 \mathrm{~V}$ (the dotted line is $\mathrm{T}_{\mathrm{MAX}}$ and the solid line is $\mathrm{I}_{\mathrm{DS}}$ ). 
The $E_{S C}$ values were 1.05 and $1.16 \mathrm{~J} / \mathrm{cm}^{2}$ for the SJ-MOSFET and MCD SJ-MOSFET, respectively.

Figure 11 compares both devices at the same pulse of $10 \mu \mathrm{s}$, with the MCD SJ-MOSFET at $\mathrm{V}_{\mathrm{DD}}=400 \mathrm{~V}$ (the dotted line is $\mathrm{T}_{\mathrm{MAX}}$ and the solid line is $\mathrm{I}_{\mathrm{DS}}$ ). Both the short circuit current and the $\mathrm{T}_{\mathrm{MAX}}$ of the MCD SJ-MOSFET are greatly reduced compared to the SJMOSFET. For a detailed understanding of the enhanced short-circuit characteristics of the MCD SJ-MOSFET, the simulated distribution of the electron current density, electric field, lattice temperature, and hole density at point A is shown in Figure 12. Generally, the joule heating equation is expressed as follows [38]:

$$
\mathrm{q}_{\mathrm{j}}=\mathrm{J} \cdot \mathrm{E}
$$

where $\mathrm{q}_{\mathrm{j}}$ is the joule heating energy density, $\mathrm{J}$ is the current density and $\mathrm{E}$ is the electric field. Although the electric field distribution is almost same in both structures, the joule heating energy density of the proposed structure becomes smaller due to the much lower current density. It can be confirmed that the lattice temperature of the SJ-MOSFET is much higher due to the increased joule heating energy density. The highest temperature region (hot spot) of the two devices is widely distributed between the P-pillars rather than being concentrated in the JFET region, as in conventional SiC MOSFETs (i.e., non SJ devices) [35]. This is because of the SJ structure in which the electric field is distributed vertically [39]. Therefore, the hot spot is far away from the gate oxide and source metal region, resulting in high reliability. Additionally, the SJ-MOSFET features a higher hole current $\left(\mathrm{I}_{h}\right)$ than the MCD SJ-MOSFET due to the high temperature, as shown in the red line in Figure 11. This explains the high tail current of the SJ-MOSFET, and it can be confirmed that $\mathrm{I}_{\mathrm{h}}$ mainly formed at the high temperature region as shown in Figure 12. If the pulse width is further increased where $\mathrm{I}_{\mathrm{h}}$ is large enough to activate the parasitic $\mathrm{BJT}$, the drain current rises rapidly and thermal runaway occurs [25].

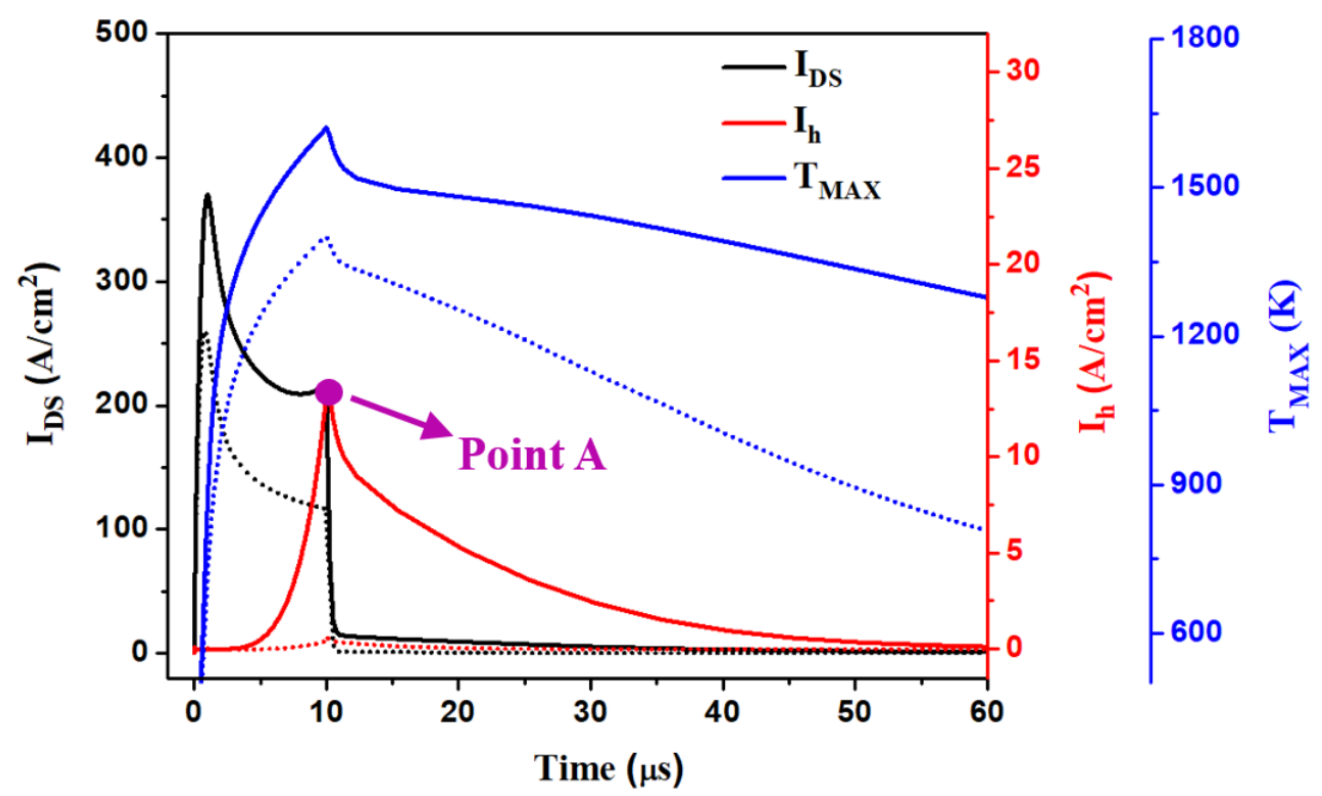

Figure 11. Comparison of short circuit characteristics at $\mathrm{V}_{\mathrm{DD}}=400 \mathrm{~V}$, and a pulse width of $10 \mu$ s (the dotted line refers to the MCD SJ-MOSFET, and the solid line refers to the SJ-MOSFET).

Finally, further investigation of the short circuit characteristics in high DC bus is conducted in a similar way. Figure 13 shows the short circuit current and the maximum temperature $\left(\mathrm{T}_{\mathrm{MAX}}\right)$ waveforms of both devices with different pulse widths at a high drain bias $\left(\mathrm{V}_{\mathrm{DD}}=600 \mathrm{~V}\right)$. The $\mathrm{t}_{\mathrm{SC}}$ and $\mathrm{E}_{\mathrm{SC}}$ were $5.5 \mu \mathrm{s}$ and $0.86 \mathrm{~J} / \mathrm{cm}^{2}$ for the SJ-MOSFET and $12 \mu \mathrm{s}$ and $0.98 \mathrm{~J} / \mathrm{cm}^{2}$ for the MCD SJ-MOSFET, respectively. The MCD SJ-MOSFET showed a $t_{S C}$ more than two times higher and an improved $E_{S C}$ compared to the SJ-MOSFET, even 
at $600 \mathrm{~V}$. It can be seen that the $\mathrm{t}_{\mathrm{SC}}$ and $\mathrm{E}_{\mathrm{SC}}$ of both devices are smaller than in the case of low drain bias. This is due to the elevated lattice temperature resulting from the high electric field, which was reported in a previous study [40]. The short circuit characteristics of both devices are summarized in Table 4 .

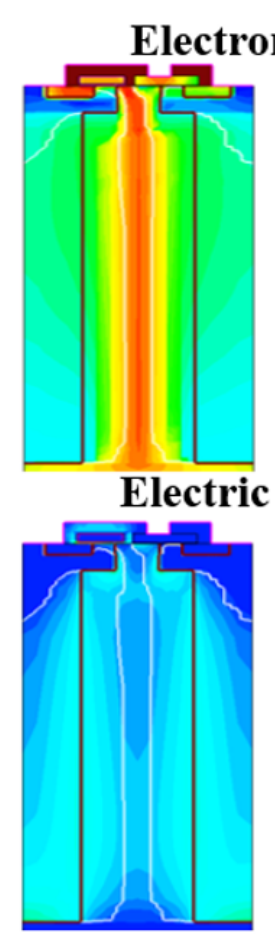

MCD-
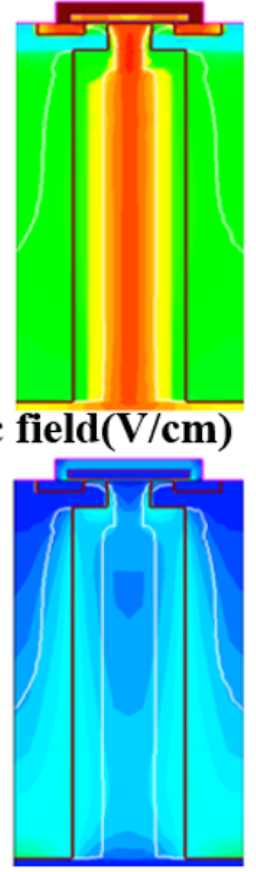

SJ-

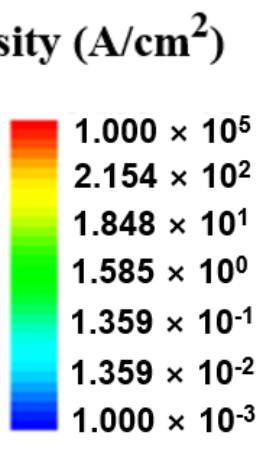

$3.300 \times 10^{6}$

$2.200 \times 10^{6}$

$1.760 \times 10^{6}$

$1.320 \times 10^{6}$

$8.800 \times 10^{5}$

$4.400 \times 10^{5}$

$0.000 \times 10^{0}$

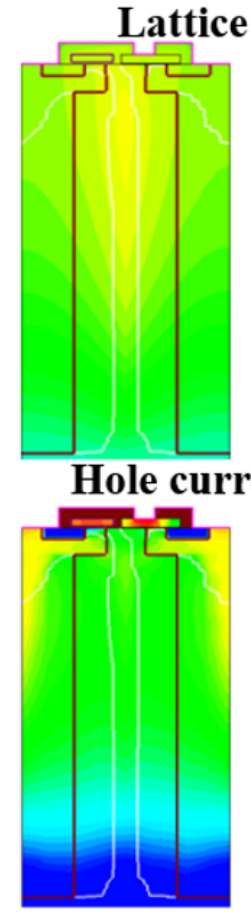

MCD-

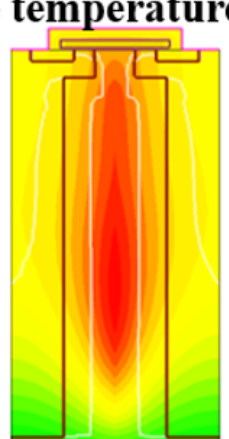

$(\mathbf{K})$
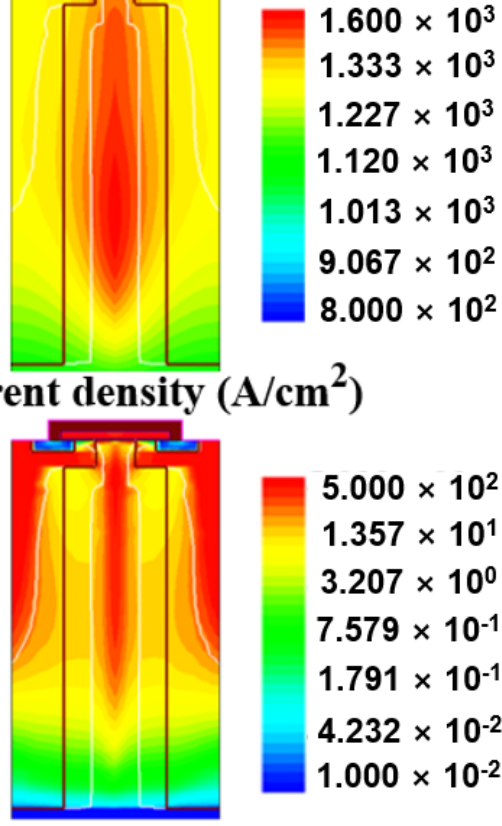

SJ-

Figure 12. Simulated distribution of electron current density, electric field, lattice temperature, and hole density at point A.

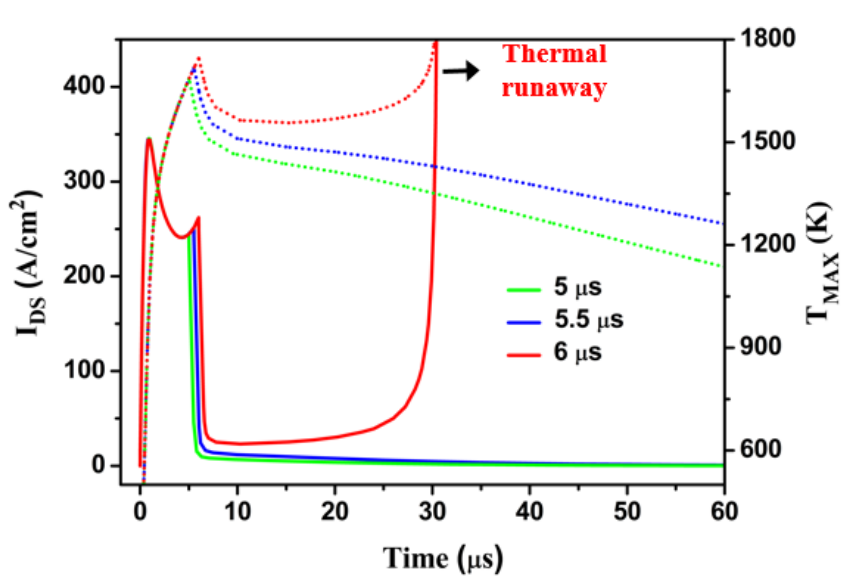

(a)

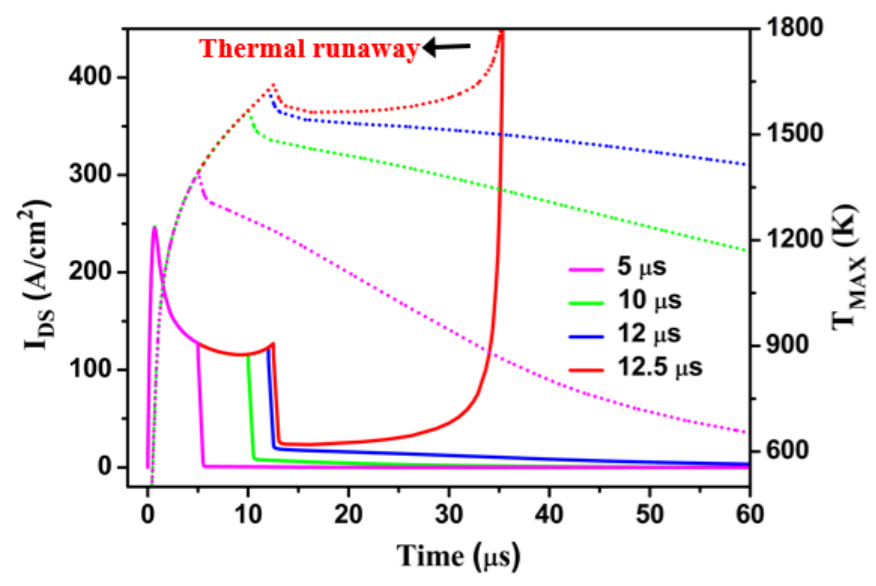

(b)

Figure 13. Simulated short circuit current and maximum temperature waveforms of the (a) SJ-MOSFET and the (b) MCD SJ-MOSFET at $\mathrm{V}_{\mathrm{DD}}=600 \mathrm{~V}$ (the dotted line is $\mathrm{T}_{\mathrm{MAX}}$ and the solid line is $\mathrm{I}_{\mathrm{DS}}$ ).

Table 4. Comparison of short circuit characteristics.

\begin{tabular}{cccc}
\hline & SJ- & MCD- & Unit \\
\hline $\mathrm{t}_{\mathrm{SC}}\left(@ \mathrm{~V}_{\mathrm{DD}}=400 \mathrm{~V}\right)$ & 11 & 22.5 & $\mu \mathrm{s}$ \\
$\mathrm{t}_{\mathrm{SC}}\left(@ \mathrm{~V}_{\mathrm{DD}}=600 \mathrm{~V}\right)$ & 5.5 & 12 & $\mu \mathrm{s}$ \\
$\mathrm{E}_{\mathrm{SC}}\left(@ \mathrm{~V}_{\mathrm{DD}}=400 \mathrm{~V}\right)$ & 1.05 & 1.16 & $\mathrm{~J} / \mathrm{cm}^{2}$ \\
$\mathrm{E}_{\mathrm{SC}}\left(@ \mathrm{~V}_{\mathrm{DD}}=600 \mathrm{~V}\right)$ & 0.86 & 0.98 & $\mathrm{~J} / \mathrm{cm}^{2}$ \\
\hline
\end{tabular}




\section{Conclusions}

In this study, a novel MCD SJ-MOSFET was developed and analyzed based on numerical TCAD simulations. Because of the P+ body and P-pillar region of the MCD SJ-MOSFET, the $t_{c o}$ of the MCD can be set at a significantly lower level, while achieving a low $E_{M O x}$ of less than $3 \mathrm{MV} / \mathrm{cm}$. Therefore, the proposed structure reduced $\mathrm{V}_{\mathrm{F}}$ by approximately half of that of the SJ-MOSFET, thus resulting in superior reverse recovery characteristics. In addition, the MCD SJ-MOSFET achieved a significantly lower $\mathrm{C}_{\mathrm{ISS}}$ and $\mathrm{C}_{\mathrm{GD}}$, thus resulting in significantly improved figures of merit $\mathrm{R}_{\mathrm{ON}} \times \mathrm{C}_{\mathrm{GD}}$ when compared with the SJ-MOSFET. As a result, the proposed structure demonstrated a shorter switching time and reduced the $\mathrm{E}_{\mathrm{SW}}$. Moreover, the simulation results revealed that the MCD SJ-MOSFET exhibited excellent short circuit characteristics in terms of the $E_{S C}$ and $t_{S C}$. As a result, the MCD SJ-MOSFET is suitable for high-frequency and high-reliability applications.

Author Contributions: All authors contributed to this work. Investigation, J.Y. and K.K.; Methodology, J.Y. and K.K.; Supervision, J.Y. and K.K.; Writing—original draft, J.Y.; Writing—review and editing, K.K. All authors have read and agreed to the published version of the manuscript.

Funding: This research received no external funding.

Data Availability Statement: Data are not available on a publicly accessible repository and they cannot be shared under request.

Acknowledgments: This research was supported by the MSIT (Ministry of Science and ICT), Korea, under the ITRC (Information Technology Research Center) support program (IITP-2021-2018-0-01421) supervised by the IITP (Institute for Information and Communications Technology Promotion), and then Samsung Electronics.

Conflicts of Interest: The authors declare no conflict of interest.

\section{References}

1. Deboy, G.; Marz, N.; Stengl, J.P.; Strack, H.A.S.H.; Tihanyi, J.A.T.J.; Weber, H.A.W.H. A new generation of high voltage MOSFETs breaks the limit line of silicon. In IEDM Tech; IEEE: San Francisco, CA, USA, 1998; pp. 683-685.

2. Udrea, F.; Deboy, G.; Fujihira, T. Superjunction Power Devices, History, Development, and Future Prospects. IEEE Trans. Electron Devices 2017, 64, 713-727. [CrossRef]

3. Masuda, T.; Saito, Y.; Kumazawa, T.; Hatayama, T.; Harada, S. $0.63 \mathrm{~m} \Omega \cdot c m 2 / 1170 \mathrm{~V} 4 \mathrm{H}$-SiC Super Junction V-Groove Trench MOSFET; IEDM: San Francisco, CA, USA, 2018; pp. 8.1.1-8.1.4.

4. Kosugi, R.; Sakuma, Y.; Kojima, K.; Itoh, S.; Nagata, A.; Yatsuo, T.; Tanaka, Y.; Okumura, H. First experimental demonstration of $\mathrm{SiC}$ super-junction (SJ) structure by multi-epitaxial growth method. In Proceedings of the IEEE 26th International Symposium on Power Semiconductor Devices \& IC's (ISPSD), Waikoloa, HI, USA, 15-19 June 2014; pp. 346-349.

5. Zhong, X.; Wang, B.; Sheng, K. Design and experimental demonstration of $1.35 \mathrm{kV}$ SiC super junction Schottky diode. In Proceedings of the 28th International Symposium on Power Semiconductor Devices and ICs (ISPSD), Prague, Czech Republic, 12-16 June 2016; pp. 231-234.

6. Kosugi, R.; Ji, S.; Mochizuki, K.; Adachi, K.; Segawa, S.; Kawada, Y.; Yonezawa, Y.; Okumura, H. Breaking the Theoretical Limit of 6.5 kV-Class 4H-SiC Super-Junction (SJ) MOSFETs by Trench-Filling Epitaxial Growth. In Proceedings of the 31st International Symposium on Power Semiconductor Devices and ICs (ISPSD), Shanghai, China, 19-23 May 2019; pp. 39-42.

7. Wang, H.; Wang, C.; Wang, B.; Ren, N.; Sheng, K. 4H-SiC Super-Junction JFET: Design and Experimental Demonstration. IEEE Electron Device Lett. 2020, 41, 445-448. [CrossRef]

8. Matsui, R.; Suzuki, D.; Tanimoto, Y.; Kitamura, M.; Kikuchihara, H.; Mattausch, H.J.; Miura-Mattausch, M. Modeling of reverse recovery effect for embedded diode in SJ MOSFET. In Proceedings of the IEEE International Conference on Electron Devices and Solid-State Circuits (EDSSC), Singapore, 1-4 June 2015; pp. 375-378.

9. Conrad, M.; DeDoncker, R.W. Avoiding reverse recovery effects in super junction MOSFET based half-bridges. In Proceedings of the IEEE 6th International Symposium on Power Electronics for Distributed Generation Systems (PEDG), Aachen, Germany, 22-25 June 2015; pp. 1-5.

10. Yamashita, N.; Murakami, N.; Yachi, T. Conduction power loss in MOSFET synchronous rectifier with parallel-connected Schottky barrier diode. IEEE Trans. Power Electron. 1998, 13, 667-673. [CrossRef]

11. Vudumula, P.; Kotamraju, S. The reverse recovery characteristics of an SiC superjunction MOSFET with a p-type Schottky diode embedded at the drain side for improved reliability. J. Comput. Electron. 2021, 20, 1187-1195. [CrossRef]

12. Kotamraju, S.; Vudumula, P. Improved reverse recovery characteristics obtained in $4 \mathrm{H}-\mathrm{SiC}$ double-trench superjunction MOSFET with an integrated p-type Schottky diode. IET Circuits Devices Syst. 2020, 14, 1283-1288. [CrossRef] 
13. Zhang, Y.; Yang, X.; Chen, H.; Li, K.; Zhong, W.; Luo, M.; Luo, J.; Zhang, B.; Bai, S. Investigating the Failure Mechanism of Short-Circuit Tests in 1.2-kV SiC JBS-Integrated MOSFETs. IEEE Trans. Electron Devices 2020, 67, 4027-4032. [CrossRef]

14. Okawa, M.; Aiba, R.; Kanamori, T.; Kobayashi, Y.; Harada, S.; Yano, H.; Iwamuro, N. First Demonstration of Short-Circuit Capability for a $1.2 \mathrm{kV}$ SiC SWITCH-MOS. IEEE J. Electron Devices Soc. 2019, 7, 613-620. [CrossRef]

15. Aiba, R.; Matsui, K.; Baba, M.; Harada, S.; Yano, H.; Iwamuro, N. Demonstration of Superior Electrical Characteristics for 1.2 kV SiC Schottky Barrier Diode-Wall Integrated Trench MOSFET with Higher Schottky Barrier Height Metal. IEEE Electron Device Lett. 2020, 41, 1810-1813. [CrossRef]

16. Okawa, M.; Kanamori, T.; Aiba, R.; Yano, H.; Iwamuro, N.; Harada, S. Analysis of 1.2 kV SiC SWITCH-MOS after Short-circuit Stress. In Proceedings of the 32nd International Symposium on Power Semiconductor Devices and ICs (ISPSD), Vienna, Austria, 13-18 September 2020; pp. 74-77.

17. Zhang, M.; Wei, J.; Zhou, X.; Jiang, H.; Li, B.; Chen, K.J. Simulation Study of a Power MOSFET with Built-in Channel Diode for Enhanced Reverse Recovery Performance. IEEE Electron Device Lett. 2019, 40, 79-82. [CrossRef]

18. Li, P.; Guo, J.; Lin, Z.; Hu, S. A Power MOSFET with P-Base Schottky Diode and Built-In Channel Diode for Fast Reverse Recovery. IEEE J. Electron Devices Soc. 2021, 9, 300-305.

19. Zhou, X.; Pang, H.; Jia, Y.; Hu, D.; Wu, Y.; Tang, Y.; Xia, T.; Gong, H.; Zhao, Y. SiC Double-Trench MOSFETs with Embedded MOS-Channel Diode. IEEE Trans. Electron Devices 2020, 67, 582-587. [CrossRef]

20. Zhou, X.; Gong, H.; Jia, Y.; Hu, D.; Wu, Y.; Xia, T.; Pang, H.; Zhao, Y. SiC Planar MOSFETs With Built-In Reverse MOS-Channel Diode for Enhanced Performance. IEEE J. Electron Devices Soc. 2020, 8, 619-625. [CrossRef]

21. Krishnaswami, S.; Das, M.; Hull, B.; Ryu, S.H.; Scofield, J.; Agarwal, A.; Palmour, J. Gate oxide reliability of 4H-SiC MOS devices, IEEE International Reliability Physics Symposium. In Proceedings of the 43rd Annual, San Jose, CA, USA, 17-21 April 2005; pp. 592-593.

22. Ye, Z.Y.; Liu, L.; Yao, Y.; Lin, M.Z.; Wang, P.F. Fabrication of a 650V Superjunction MOSFET with Built-in MOS-Channel Diode for Fast Reverse Recovery. IEEE Electron Device Lett. 2019, 40, 1159-1162. [CrossRef]

23. Synopsys Inc. Sentaurus Device Manual, User Manual, Version O-2016.06; Synopsys Inc.: Mountain View, CA, USA, 2016.

24. Han, Z.; Bai, Y.; Chen, H.; Li, C.; Lu, J.; Song, G.; Liu, X. A trench/planar SiC MOSFET integrated with SBD (TPSBD) for low reverse recovery charge and low switching loss. Semicond. Sci. Technol. 2020, 35, 10. [CrossRef]

25. Chen, X.; Chen, H.; Shi, B.; Wang, Y.; Li, X.; Zhou, C.; Li, C.; Deng, X.; Luo, H.; Wu, Y.; et al. Investigation on Short-Circuit Characterization and Optimization of 3.3-kV SiC MOSFETs. IEEE Trans. Electron Devices 2021, 68, 184-191. [CrossRef]

26. Ni, W.; Wang, X.; Xu, M.; Li, M.; Feng, C.; Xiao, H.; Jiang, L.; Li, W.; Wang, Q. Comparative Study of SiC Planar MOSFETs with Different p-Body Designs. IEEE Trans. Electron Devices 2020, 67, 1071-1076. [CrossRef]

27. Baliga, B.J. Advanced High Voltage Power Device Concepts, 1st ed.; Springer: Cham, Switzerland, 2011; pp. 481-489.

28. Reigosa, P.D.; Schulz, N.; Minamisawa, R. Short-circuit robustness of retrograde channel doping 1.2 kV SiC MOSFETs. Microelectron. Reliab. 2021, 120, 114117. [CrossRef]

29. Sung, W.; Baliga, B.J. On Developing One-Chip Integration of $1.2 \mathrm{kV} \mathrm{SiC} \mathrm{MOSFET} \mathrm{and} \mathrm{JBS} \mathrm{Diode} \mathrm{(JBSFET).} \mathrm{IEEE} \mathrm{Trans.} \mathrm{Ind.}$ Electron. 2017, 64, 8206-8212. [CrossRef]

30. Ishigaki, T.; Hayakawa, S.; Murata, T.; Masuda, T.; Oda, T.; Takayanagi, Y. Diode-Less SiC Power Module with Countermeasures Against Bipolar Degradation to Achieve Ultrahigh Power Density. IEEE Trans. Electron Devices 2020, 67, 2035-2043. [CrossRef]

31. Sampath, M.; Morisette, D.T.; Cooper, J.A. Constant-Gate-Charge Scaling for Increased Short-Circuit Withstand Time in SiC Power Devices. In Proceedings of the IEEE International Reliability Physics Symposium (IRPS), Dallas, TX, USA, 28 April-30 May 2020; pp. 1-4.

32. Vudumula, P.; Kotamraju, S. Design and Optimization of 1.2-kV SiC Planar Inversion MOSFET Using Split Dummy Gate Concept for High-Frequency Applications. IEEE Trans. Electron Devices 2019, 66, 5266-5271. [CrossRef]

33. Wei, J.; Liu, S.; Tong, J.; Zhang, X.; Sun, W.; Huang, A.Q. Understanding Short-Circuit Failure Mechanism of Double-Trench SiC Power MOSFETs. IEEE Trans. Electron Devices 2020, 67, 5593-5599. [CrossRef]

34. Qin, H.; Dong, Y.; Xu, K.; Xu, H.; Fu, D.; Wang, S.; Zhao, C. A comprehensive study of the short-circuit characteristics of SiC MOSFETs. In Proceedings of the 12th IEEE Conference on Industrial Electronics and Applications (ICIEA), Siem Reap, Cambodia, 18-20 June 2017; pp. 332-336.

35. Romano, G.; Fayyaz, A.; Riccio, M.; Maresca, L.; Breglio, G.; Castellazzi, A.; Irace, A. A Comprehensive Study of Short-Circuit Ruggedness of Silicon Carbide Power MOSFETs. IEEE J. Emerg. Sel. Top. Power Electron. 2016, 4, 978-987. [CrossRef]

36. Castellazzi, A.; Fayyaz, A.; Yang, L.; Riccio, M.; Irace, A. Short-circuit robustness of SiC Power MOSFETs: Experimental analysis. In Proceedings of the IEEE 26th International Symposium on Power Semiconductor Devices \& IC's (ISPSD), Waikoloa, HI, USA, 15-19 June 2014; pp. 71-74.

37. Kakarla, B.; Tsibizov, A.; Stark, R.; Badstübner, I.K.; Grossner, U. Short Circuit Robustness and Carrier Lifetime in Silicon Carbide MOSFETs. In Proceedings of the 32nd International Symposium on Power Semiconductor Devices and ICs (ISPSD), Vienna, Austria, 13-18 September 2020; pp. 234-237.

38. Aikio, A.T.; Selkälä, A. Statistical properties of Joule heating rate, electric field and conductances at high latitudes. Ann. Geophys. 2009, 27, 2661-2673. [CrossRef] 
39. Okada, M.; Kyogoku, S.; Kumazawa, T.; Saito, J.; Morimoto, T.; Takei, M.; Harada, S. Superior Short-Circuit Performance of SiC Superjunction MOSFET. In Proceedings of the 32nd International Symposium on Power Semiconductor Devices and ICs (ISPSD), Vienna, Austria, 13-18 September 2020; pp. 70-73.

40. Namai, M.; An, J.; Yano, H.; Iwamuro, N. Investigation of shoet-circuit failure mechanisms of SiC MOSFETs by varying DC bus voltage. Jpn. J. Appl. Phys. 2018, 57, 7. [CrossRef] 